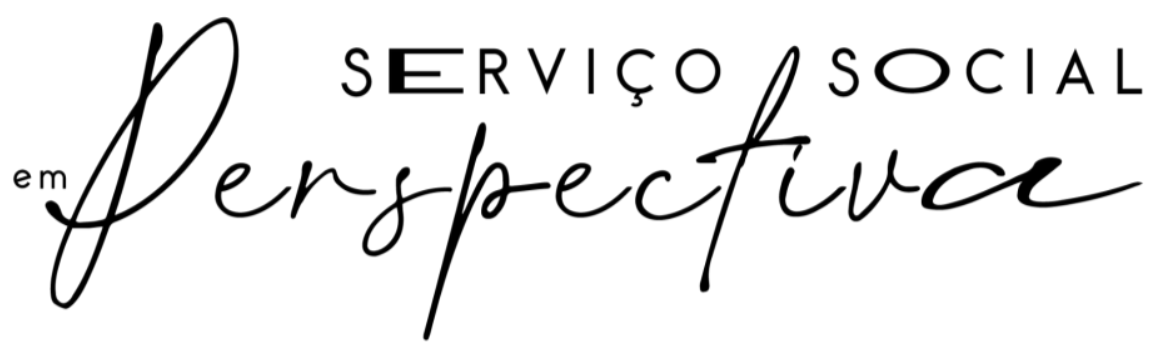

Montes Claros (MG), volume 5, número 1. jan./jun. 2021. I ISSN 2527-1849

\title{
A COVID-19 E SEUS IMPACTOS NO SISTEMA PRISIONAL EM SERGIPE
}

\section{COVID-19 AND ITS IMPACTS ON THE PRISON SYSTEM IN SERGIPE}

Paulo Roberto Felix dos Santos 1

Izy Rebeka Gomes Lima2

Maria Suelen Santos ${ }^{3}$

Resumo: Diante da situação de crise sanitária ocasionada pela pandemia da Covid-19. nos marcos da crise do capital, torna-se necessário explicitar como esse cenário impacta a dinâmica prisional, com ênfase na realidade sergipana. O presente artigo tem como objetivo principal proporcionar um processo reflexivo-crítico acerca da configuração do sistema prisional em Sergipe em tempos de pandemia, com uma revisão bibliográfica e pesquisa documental, a partir do materialismo histórico dialético como método de análise. Identificamos como as condições precarizadas do sistema prisional propiciam a expansão da pandemia, expondo seus(uas) internos(as) às mais variadas violações de direitos e situações de matabilidade. Tais impactos revelam-se mais contundentes perante a juventude negra e pobre. que compõe a maior parte da população prisional, processo que escancara as particularidades da dimensão do racismo estrutural e do projeto de controle sociorracial. Ademais, demonstramos algumas das medidas utilizadas para mitigar os efeitos da pandemia nesse espaço que, apesar de importantes, revelam-se limitadas diante de todo o cenário caótico do cárcere sergipano. Como poderemos perceber, tais elementos explicitam os fundamentos das medidas de aprisionamento e das formas de controle capitalista mobilizadas em face do excedente de força de trabalho, e no contexto de pandemia tem essa condição agravada nas prisões.

Palavras-chave: Sistema Prisional. Racismo Estrutural. Pandemia. Sergipe.

\begin{abstract}
In view of the health crisis situation, caused by the Covid-19 pandemic, within the framework of the capital crisis, it is necessary to explain how this scenario impacts the prison dynamics, with an emphasis on Sergipe's reality. The main objective of this article is to provide a reflective-critical process about the configuration of the prison system in Sergipe in times of pandemic, with a bibliographic review and documentary research, based on historical dialectical materialism, as a method of analysis. We identified how the precarious conditions of the prison system favor the expansion of the pandemic, exposing its inmates to the most varied violations of rights and situations of killings. Such impacts are most striking in the face of black and poor youth, who make up the majority of the prison population, a process that opens up the particularities of the dimension of structural racism, and of the project of socio-racial control. In

\footnotetext{
1 Assistente Social. Doutor em Serviço Social pelo PPGSS/UFRJ. Docente do Curso de Serviço Social da Universidade Federal de Sergipe. Lider do Grupo de Estudos e Pesquisas Marxistas (GEPEM/UFS). E-mail: fellix.ufs@gmail.com

2 Graduanda do Curso de Serviço Social da Universidade Federal de Sergipe. E-mail: izy_rgl@hotmail.com

3 Graduanda do Curso de Serviço Social da Universidade Federal de Sergipe. E-mail: maria.suellem@gmail.com
} 
addition, we demonstrate some of the measures used to mitigate the effects of the pandemic in this space. which, although important, are limited, given the whole chaotic scenario of Sergipe's prison. As we can see. these elements explain the fundamentals of the imprisonment measures and the forms of capitalist control mobilized in the face of the surplus of the workforce, and that in the context of a pandemic this condition is aggravated in prisons.

Keywords: Prison System. Structural Racism. Pandemic. Sergipe.

INTRODUÇÃO

No âmbito estrutural do desenvolvimento capitalista, a gênese da pena tem como marco o período da chamada "acumulação primitiva" (MARX, 2013). Tem-se, assim, a partir do trabalho alienado e de sua "submissão forçada" ao capital, uma solução para a condição dos(as) expropriados(as) dos meios de produção, que passam a ocupar a força de trabalho das fábricas capitalistas ou engrossam as fileiras do desemprego, da mendicância, ou são submetidos(as) ao espaço da prisão, como demonstraram as análises de Marx (2013) e Mellosi e Pavarini (2017).

No Brasil, tendo sua dinâmica estrutural particular assentada inicialmente em um desenvolvimento capitalista de matriz escravocrata-colonial, o sistema prisional, no decorrer de sua história, sofreu as influências dessas determinações que estruturam a formação social do país, principalmente ao considerarmos a relação entre os(as) pioneiros(as), os processos de acumulação do capitalismo e o surgimento do sistema penal. Para a massa da população, desprovida até mesmo da possibilidade da subsunção de seu trabalho ao capital, sobretudo no período pós-escravização, o que restou foi a penalização e o encarceramento, quando não a própria "política de extermínio", como mecanismo de regulação da "gestão do excedente", composta, majoritariamente, pela população negra, pobre, com baixa escolarização.

Diante disso, as instituições e os(as) agentes responsáveis pelo sistema prisional evidenciam, na consolidação de suas bases estruturais, o contexto determinado a partir da formação social e histórica que se instaura não somente nesses espaços, mas na sociedade em geral, determinada pelo "racismo estrutural" (ALMEIDA, 2018). A prisão retrata, no plano fenomênico, o "descaso", a "precarização" e a "desresponsabilização" por parte do Estado em relação à população que é determinada para ocupar esses locais, mas que, a rigor, evidencia as estruturas medulares sobre as quais se instaura a razão de ser do aparelho estatal. necessário ao desenvolvimento do capital (MÉSZAROS, 2002) e de suas formas punitivas. 
Com a crise sanitária ocasionada pela Covid-19, tem-se um processo em que se acirram as desigualdades socioestruturais e raciais. Ainda que a expansão virótica se espalhe de modo ampliado, abarcando o planeta e espraiando-se por todas as camadas sociais, é fato que seus impactos e índices de letalidade revelam as implicações às camadas mais pauperizadas da sociedade. No Brasil, essas implicações se fizeram sentir de modo mais contundente não só entre os estratos mais pauperizados da classe trabalhadora, mas junto à população negra enquanto perfil predominante daquela camada.

Esse cenário tende a ser agravado se levarmos em consideração as pessoas que se encontram em situação de privação de liberdade. Para avaliarmos esse cenário, em tempos de pandemia, buscamos situar as implicações da pandemia no âmbito do sistema prisional sergipano enquanto particularidade da realidade nacional, guardando em sua dinâmica sociorreprodutiva as marcas que configuram a própria "estrutura pandêmica" do sistema prisional brasileiro e seu processo permanente de violação de direitos.

A execução do artigo decorrerá de revisão bibliográfica e pesquisa documental, a partir de dados em noticiários de mídia, de levantamentos e relatórios disponibilizados por instituições que compõem o sistema jurídico-penal brasileiro, a exemplo do Sistema de Informações Penitenciárias (Infopen), de relatórios da Ordem dos Advogados do Brasil (OAB) e do Conselho Nacional de Justiça (CNJ), a partir de uma problematização crítico-dialética, buscando evidenciar as contradições que conformam o fenômeno em questão e seu significado na sociabilidade atual.

Para essa análise, buscamos situar o sistema prisional sergipano nos marcos estruturais da dinâmica nacional, ainda que conservando determinadas particularidades. Por isso, foi fundamental uma mirada quanto à caracterização do sistema no estado, bem como o perfil de sua população prisional, buscando identificar quais as condições que propiciam a expansão do vírus, bem como quem tem maiores potencialidades de ser impactadolal com esse movimento. Em outro momento, apresentamos o panorama quanto à incidência do vírus, bem como as ações (ou ausência delas) que foram mobilizadas de modo a mitigar os efeitos da pandemia.

É importante frisar que o estudo dessa "problemática", agravada no contexto da pandemia, nos faz refletir sobre o sistema prisional sergipano, bem como o nacional, a 
população que o compõe, as dificuldades enfrentadas pelos(as) internos(as) e familiares, e as forças em disputa na luta contra a violação dos direitos humanos em todo o processo que vai desde antes da entrada desses(as) usuários(as) no cárcere, na própria internação, mas também no processo pós-encarceramento, e que tem na superestrutura violenta, de cariz conservador, amplificada pelo "populismo penal", seus reflexos nos poderes legislativo. executivo e judiciário.

\section{O LUGAR DO SISTEMA PRISIONAL SERGIPANO NA PARTICULARIDADE DO CENÁRIO BRASILEIRO}

A formação sócio-histórica do Brasil foi fruto de um processo desigual, tendo como base, inicialmente, o trabalho escravizado no período colonial e, em seguida, a exploração da força de trabalho a partir do processo de rápida industrialização e urbanização, com o incentivo do trabalho imigrante, sendo o(a) negrola) "descartado(a)" desse processo, restandoThe apenas condições precárias de trabalho e de vida (FERNANDES, 2008). Diante dessa opção pelo trabalho imigrante, sob a justificativa de qualificação e consequente descarte do(a) negro(a) nesse processo, demonstra-se o interesse em branquear o país.

Na análise das determinações que vêm conformando historicamente o modelo prisional brasileiro, devem-se destacar os elementos estruturantes do sistema de justiça criminal, nos marcos de sua configuração internacional, entrelaçados às particularidades da formação social e histórica do país. Seus pressupostos podem ser localizados ainda no Brasil-colônia, na produção e reprodução de determinadas relações sociais, tendo no racismo sua base fundamental para criminalizar negros(as), e que, no decorrer de toda dinâmica histórica, reconfigura-se, conservando suas bases. Nesse sentido, por ser estrutural,

[...] o racismo perpassa todas as instituições e relações na sociedade. Mas o sistema criminal ganha outros contornos mais profundos neste processo. Mais do que perpassado pelo racismo, o sistema criminal é construido e ressignificado historicamente, reconfigurando e mantendo esta opressão que tem na hierarquia racial um dos pilares de sustentação. (BORGES, 2019, p. 44). 
Vale destacar que as diferentes experiências da constituição do sistema prisional no país guardam as marcas da seletividade sociorracial, que atravessaram o processo que vai da colonização aos dias atuais, passando pelo momento pós-abolição sob o mito da constituição de uma "democracia racial" no país (FERNANDES, 2008; NASCIMENTO, 1977). Ainda que se metamorfoseando historicamente, o sistema de justiça criminal tem funcionado, para utilizar a expressão de Alexsander (2017), como um "sistema racializado de controle social".

Em Sergipe, essa dinâmica que estrutura os mecanismos de controle social da realidade brasileira também é reproduzida. Seu sistema prisional não se diferencia do contexto sinalizado, uma vez que está inserido em um mesmo processo histórico, com determinações concretas que particularizam a sua realidade. Em meados do final do século XIX, no estado de Sergipe, de acordo com Santos (2012), foi construida a primeira unidade prisional, a Cadeia Pública de Sergipe (Cadeião). Antes disso, esses individuos eram "despejados" em casebres alugados. Segundo a autora, a reclusão com trabalho era o mecanismo utilizado como forma de reinserir na sociedade aqueles(as) que infringissem as leis - porém, a Cadeia Pública de Sergipe, em virtude da má administração, foi extinta.

Em 1872 foi regulamentada a "Casa da Prisão" de Aracaju, sendo instalados, em 1878, setores de enfermaria, escola, oficinas e capela. $\bigcirc$ método de regeneração assentava-se no tripé instrução, trabalho e religião (católica):

A primeira traria ao encarcerado a luz da razão (função correcional): o segundo possibilitaria a reflexão sobre o crime no silêncio do oficio, e utilidade social (função exemplar): e a terceira, garantiria a proximidade com o "Bem" (função moralizadora). O tripé regenerador sanaria os males-físico emocionais, sociais, e morais, seria uma panacéia para os presos. Esta ideia de reforma penitenciária está sintetizada na seguinte sentença em voga na época: "Se o criminoso é um enfermo; a pena um remédio; o cárcere um hospital" (FONTES, 1877, apud SANTOS, 2012, p. 92).

Esse método foi implantando na "Casa de Prisão", porém não obteve êxito. Nesses locais, na fase provincial, o quantitativo de encarcerados(as) já era um fator que tendia a um crescente aumento, já que todos(as) os(as) presos(as) da província eram enviados(as) para a capital. Sobre a alimentação e vestuários dos(as) usuários(as), as reclamações se faziam presentes, estabelecendo posteriormente acordos com terceiros para o fornecimento de 
alimentação para evitar a entrada de mulheres no ambiente para levar alimentos, dificultando a entrada de drogas, bebidas alcoólicas e armas (SANTOS, 2012).

Consoante à dinâmica particular da realidade brasileira, observa-se a predominância de pressupostos ideopolíticos de cariz conservador na estruturação do sistema prisional em Sergipe, traduzido em valores disseminados pela elite intelectual da época. É possível destacar. por exemplo, a "valorização do trabalho" como um forte discurso produzido pelas autoridades públicas e a igreja católica no século XIX.

\begin{abstract}
Esta ideia parecia paradoxal numa sociedade marcada pela ordem escravocrata em que o trabalho era associado a uma imagem ignóbil. No entanto, o poder público uniuse à igreja católica para propagar a valorização do trabalho livre devido, por um lado, à escassez de mão-de-obra escrava com a proibição do tráfico de africanos desde 1850, e por outro, à mitigação da escravidão com a sanção de leis abolicionistas na segunda metade do século XIX. (SANTOS, 2012, p. 93-94).
\end{abstract}

O cárcere seria um estabelecimento propício para atingir, por meio dessa "valorização do trabalho", os objetivos vinculados ao Estado, através da manutenção da força de trabalho também nesses espaços, para o processo de acumulação, apropriação e repartição da riqueza por uma minoria, a partir da exploração dos(as) que ali se encontram encarcerados(as). Verificase uma articulação, em interações reciprocas, entre o cárcere e a fábrica, ou, dito de outro modo, entre os mecanismos de disciplinar e punir trabalhadores(as) e a adequação para a inserção no "mercado de trabalho capitalista" (MELLOSI; PAVARINI, 2017). Atualmente, tal exploração não é mais definida sob a égide da escravidão, mas sob uma exploração que mascara as correntes do periodo escravocrata num novo modo de produzir e acentuar as desigualdades sociais para todos(as) aqueles(as) que são "excluidos(as)" e "marginalizados(as)" nessa ordem.

Santos (2012) salienta os termos utilizados pelo Arcebispo Primaz do Brasil. D. Romualdo Antônio de Seixas - Marquês de Santa Cruz (1784-1860), para com os marginalizados, como forma de valorizar o trabalho livre dirigido por uma elite senhorial: partia da defesa do "recrutamento de 'vadios', 'mendigos', 'vagabundos', 'ociosos' e 'indolentes'. De acordo com Santos (2012, p. 94), "[e]ra essa 'casta de gente miúda' que regurgitava nas cadeias públicas sergipenses do século XIX". A autora ainda destaca que a "Casa de Prisão" foi extinta no 
início do século $X X$, sendo construída a Penitenciária de Aracaju em seu lugar, no Bairro América. Nota-se que os fundamentos que estruturam os primórdios do sistema prisional no estado - sua dinâmica, funcionalidade e valores - se associam ao processo de constituição das relações de assalariamento de uma grande parcela de ex-escravizados(as); corpos que necessitam - pelo binômio consenso/repressão - ser reorientados à nova fase de acumulação de capital em Sergipe.

\section{CARACTERISTICAS E CONDIÇÕES PROPICIADORAS À EXPANSÃO DA COVID-19}

Com a chegada da pandemia do novo coronavírus, a Covid-19, no Brasil, em março de 2020, um pavor passou a fazer parte da vida de todos(as). É válido registrarmos, entretanto, que pavor já é um sentimento constante na vida dos(as) internos(as) do sistema prisional no país, sobretudo em tempos de recrudescimento da politica de "encarceramento em massa" (BORGES, 2019; WACQUANT, 2011), que vem contribuindo para um processo de superlotação dos presidios. Se entre 2000 e 2017 a taxa de aprisionamento no Brasil - que é calculada pela razão entre o número total de pessoas privadas de liberdade e a quantidade populacional do país, com a razão obtida multiplicada por 100 mil - aumentou mais de 150\% em todo país, em Sergipe esse número representou 213,63\%, segundo levantamento do Depen (2017), algo que aponta tendências ainda mais graves do que a média nacional.

Vale ressaltar que nem todos(as) esses(as) internos(as) já tiveram seu julgamento realizado, estando, portanto, aguardando ainda sentença. De acordo com o Anuário Brasileiro de Segurança Pública, publicado pelo Fórum Brasileiro de Segurança Pública (FBSP, 2019, p. 201). "ao final de 2017 cerca de 32\% da população prisional brasileira ainda aguardava o julgamento. E em alguns estados a situação seria mais dramática, como são os casos do Piauí (60\%), Amazonas $(53,8 \%)$ e Sergipe $(51,6 \%)^{\prime \prime}$. Verifica-se que Sergipe ocupava a terceira colocação no ranking nacional em relação ao número de internos sem julgamento, denotando graves violação a direitos fundamentais, e que numa situação de calamidade sanitária têm as vidas expostas a um risco ainda maior. 
A partir dos dados disponibilizados pelo site Infopen, atualizados no período de junho de 2020, em Sergipe o quantitativo de presos(as) sob a administração da Se juc ${ }^{4}$ contabilizava o total de 6.244 pessoas. De acordo com o relatório da Ordem dos Advogados do Brasil, Seccional Sergipe-OAB/SE, realizado em 2018, havia uma superlotação no sistema carcerário do estado, com uma estimativa total de 5.274 presos(as) para uma capacidade de 2.199 pessoas, tendo, ao todo, oito unidades prisionais ${ }^{5}$ (OAB, 2018). No que condiz à estrutura dessas prisões, as que destacam piores condições são o Copemcan e o Preslen. Ambos compartilham de péssimas estruturas, superlotação e o contágio de diversas doenças.

A superlotação das celas, sua precariedade e sua insalubridade tornam as prisões num ambiente propicio à proliferação de epidemias e ao contágio de doenças. Todos esses fatores estruturais aliados ainda à má alimentação dos presos, seu sedentarismo, o uso de drogas, a falta de higiene e toda a lugubridade da prisão, fazem com que um preso que adentrou lá numa condição sadia, de lá não saia sem ser acometido de uma doença ou com sua resistência fisica e saúde fragilizadas. (ASSIS, 2007 apud ARAÚJO et al.. 2014, p. 60).

Os presídios sergipanos, funcionando como mecanismos permanentes de violação de direitos, reafirmam também o cenário que o Supremo Tribunal Federal (STF) atestou como um "estado de coisas inconstitucional" (JUSTIFICANDO, 2020). Verifica-se que as condições não destoam da tendência da situação nacional, onde tais espaços passam a se assemelhar a "campos de concentração para pobres, ou com empresas públicas de depósito industrial dos dejetos sociais, do que com instituições judiciárias servindo para alguma função penalógica dissuasão, neutralização ou reinserção" -, conforme indicou Wacquant (2011, p.13).

Vale destacar que, em um contexto de expansão da Covid-19, essa "situação pandêmica conjuntural" tende a escancarar a "violência pandêmica" (WACQUANT, 2011), fornecendo elementos propícios para a propagação do vírus, onde aumentam, em demasia, os níveis de

\footnotetext{
${ }^{4}$ Trata-se da Secretaria de Estado da Justiça, do Trabalho e de Defesa do Consumidor (Sejuc), a quem deve competir a promoção do respeito à ordem jurídica e às garantias constitucionais; a administração do Sistema Penitenciário e da Segurança Prisional (NR) (BRASIL, 2018, n.p).

${ }^{5}$ As unidades prisionais provisórias são o Complexo Penitenciário Dr. Manoel Carvalho Neto (Copemcan), a Cadeia Territorial de Nossa Senhora do Socorro (Cadeião) e o Presidio Feminino do Estado de Sergipe (Prefem). Ainda há três unidades para presos(as) provisórios(as) que possuem administração terceirizada, que são o Complexo Penitenciário Antônio Jacinto Filho (Compajaf), a Cadeia Pública de Estância e a Cadeia Pública de Areia Branca. As duas unidades destinadas ao regime fechado são: Presidio Regional Juiz Manoel Barbosa de Souza (Presmabas) e Presídio Regional Senador Leite Neto (Preslen).
} 
exposição da população prisional sergipana enquanto parte do contingente nacional. De acordo com o relatório disponibilizado pela OAB/SE (2018), a situação dos presídios em Sergipe configura espaços de superlotação, racionamento de água por dia em cada pavilhão; sem médicos e uma equipe de saúde; a falta de medicamentos; surtos de tuberculose e outras doenças contagiosas; alimentação insuficiente e de péssima qualidade. O relatório ainda complementa que

[n]ão há janelas nas celas, ficando o ambiente insuportável pela falta de ventilação, extremo calor e odor desagradável, revelando-se um verdadeiro ambiente de tortura. As celas foram projetadas para receber cerca de 12 (doze) internos, porém, a realidade atual é uma média de 33 (trinta e três) internos por cela. A higienização é feita pelos detentos, sendo que quem fornece o material de higiene e limpeza são os familiares. Apesar disso, é visível o ambiente insalubre e de condições desumanas. A água é somente fornecida por inacreditáveis, 5 (cinco) a 10 (dez) minutos/dia em cada pavilhão, situação que obriga os detentos a armazenarem água em garrafas plásticas para consumo, banho e higiene pessoal. [...] Há centenas de internos doentes, alguns em estado grave e fora constatado surto de tuberculose em todos os pavilhões. Há internos ameaçados e "jurados de morte" sem nenhum tipo de auxilio, ou previsão de transferência. A rede de esgoto de todos os pavilhões está entupida e transborda com frequência. Nos periodos de chuva, todos os pavilhões alagam (OAB, 2018, n.p).

O cenário dantesco descrito não parece diferir da realidade brasileira, como destacou a matéria realizada pelo site Justificando (2020), em referência ao Relatório Final da Comissão Parlamentar de Inquérito da Câmara dos Deputados em 2009 com dados de 2007 sobre o Sistema Carcerário. Ainda de acordo com o site, o ministro Celso de Mello relatou o seguinte no julgamento da ADPF 347/DF6:

[...] ○ Estado, agindo com absoluta indiferença em relação à gravidade da questão penitenciária, tem permitido, em razão de sua própria inércia, que se transgrida o direito básico do sentenciado de receber tratamento penitenciário justo e adequado. vale dizer, tratamento que não implique exposição do condenado a meios cruéis ou moralmente degradantes, fazendo-se respeitar, desse modo, um dos mais expressivos fundamentos que dão suporte ao Estado democrático de direito: a dignidade da pessoa humana (CF, art. 10, III)". [...] "A superlotação carcerária e a precariedade das instalações das delegacias e presidios, mais do que inobservância, pelo Estado, da ordem jurídica correspondente, configuram tratamento degradante, ultrajante e indigno a pessoas

\footnotetext{
6 Trata-se da Arguição de Descumprimento de Preceito Fundamental (ADPF) 347, na qual o Partido Socialismo e Liberdade (PSOL) solicitou ao Supremo Tribunal Federal (STF) que se reconheça a violação de direitos fundamentais da população carcerária e seja determinada a adoção de diversas providências no tratamento da questão prisional do país.
} 
que se encontram sob custódia". [...] "As penas privativas de liberdade aplicadas em nossos presidios convertem-se em penas cruéis e desumanas. Os presos tornam-se 'lixo digno do pior tratamento possível', sendo-lhes negado todo e qualquer direito à existência minimamente segura e salubre. (JUSTIFICANDO, 2020).

Em Sergipe, destacamos, em nível ilustrativo, a situação da Cadeia Pública (Cadeião), localizada na cidade de Nossa Senhora do Socorro, que contava em 2018 com 264 internos(as), mas com a capacidade de lotação de 160 (cento e sessenta). Os problemas que se apresentam nessa unidade eram, à época: superlotação; falta de atendimento médico e de medicamentos; surtos epidêmicos, havendo situações de explícita violação de direitos humanos IOAB/SE, 2018). Ademais, são péssimas as estruturas do prédio, o que possibilita o contágio por meio de doenças infectocontagiosas, tanto em relação aos(às) usuários(as) ali encarcerados(as) quanto àqueles(as) que mantêm com eles algum tipo de contato.

Diante de todo esse cenário, a conclusão que se tem, segundo a OAB (2018), é que, de fato, a situação do sistema prisional no estado de Sergipe é gravissima, com destaque para a maior unidade prisional do estado, o Complexo Penitenciário Dr. Manoel Carvalho Neto (Copemcan), e para o Presidio Regional Senador Leite Neto (Preslen). Para a entidade, "essas unidades são verdadeiras masmorras medievais, afrontando todos os direitos e garantias fundamentais previstos na Carta Magna" IOAB, 2018). Além de flagrante violação à Constituição Federal, verificamos a desconsideração ao disposto na Lei de Execuções Penais (LEP) no sentido de "proporcionar condições para a harmônica integração social do condenado e do internado" (BRASIL, 1984). Além disso, ignora o que prevê a legislação no âmbito da assistência, educação, saúde e trabalho aos(às) internos(as). Conforme Araújo et al. (2014, p. 65-66),

[n]ota-se a ausência do Estado num trabalho com ações preventivas, no sentido de neutralizar possiveis doenças contagiosas e epidêmicas no sistema prisional. Neste sentido, ações preventivas são de extrema importância para reduzir os niveis de doenças nos estabelecimentos penais, e com isso, consequentemente representará um custo efetivo por detento bem menor que os atuais.

Todo esse complexo de questões reveladoras dos traços estruturantes do sistema prisional brasileiro e sergipano manifesta-se como chave de análise que atesta como o Estado 
vem tratando de seus(suas) presos(as), submetendo-os(as) à condição de "vidas inúteis", passiveis das piores condições, de caráter inumano, elementos recrudescidos em tempos de crise estrutural do capital (MÉSZÁROS, 2002) e do aumento do controle sobre os segmentos mais pauperizados da classe trabalhadora. Mais que um erro ou descaso frente a esse quadro, - que se revela mais patente é a funcionalidade do Estado (burguês) como mecanismo permanente de controle e gestão dessa força de trabalho excedentária (MARX, 2013; MÉSZAROS, 2002). Nesse sentido, vale destacar a "política de encarceramento em massa", mobilizada como política permanente de violação de direitos, inclusive do direito à vida (digna). Ainda mais revelador da natureza desse processo é quando nos voltamos ao perfil predominante dessa população, e os elementos que jungem essas determinações com a estrutura constitutiva da formação social brasileira.

QUEM SOFRE COM AS CONDIÇÕES ESTRUTURAIS DOS PRESÍDIOS E TORNA-SE MAIS EXPOSTO(A) À PANDEMIA?

O caráter degradante dos presídios brasileiros, e em particular sergipanos, longe de operar por meio de uma mítica "incorporação democrática" do seu "público-alvo", o faz não só por meio de uma seletividade penal, mas, sobretudo, a partir de marcadores sociorraciais, punindo a população pobre e negra das nossas cidades (BORGES, 2019; ALEXSANDER, 2017). No âmbito da identificação da etnia/raça dos(as) internos(as) do sistema prisional sergipano. destacam-se os dados do Depen (2019), que indicam, quando agregados os números dos(as) declarados(as) pretos(as) ou pardos(as), um percentual de negros(as) em torno de 81,7\%, bem acima da média nacional, de 66,69\%, caracterizando a negritude do sistema prisional sergipano. não só demonstrando uma sintonia com a tendência nacional, mas superando-a, em muito. Não se trata, portanto, de um perfil multicultural (BORGES, 2019), mas racialmente determinado. Revela-se patente que "o sistema de justiça criminal tem profunda conexão com o racismo", tendo suas "engrenagens mais do que perpassados por essa estrutura de opressão, mas o aparato reordenado para garantir a manutenção do racismo e, portanto, das desigualdades baseadas na hierarquização racial" (BORGES, 2019, p. 21-22). 
A maior parte desses individuos negros(as) é jovem, recrutada nos estratos mais periféricos do estado, o que indica a intensificação da criminalização da juventude pobre sergipana. No perfil dessa juventude de aprisionados(as), verificamos que 55,8\% têm menos de 30 anos, e 41,13\% têm entre 30 e 45 anos de idade. Assim, como no Brasil, o estado de Sergipe caracteriza-se por uma população prisional majoritariamente jovem, o que evidencia a contradição própria ao modo de produção capitalista, e quem compõe o sistema prisional são também os que compõem a classe operária, aquele excedente de força de trabalho desqualificada e de baixa escolarização.

Alijada das oportunidades de acesso a uma condição mínima de cidadania, à população negra brasileira/sergipana resta, como as únicas oportunidades, o trabalho informal, os piores postos de trabalho, as favelas, os cortiços, as péssimas condições de vida, o tráfico de drogas, o extermínio, além do cárcere. Nesse último, verifica-se um processo permanente de controle social de caráter racialmente seletivo. Desse modo,

[t]anto o cárcere quanto o pós-encarceramento significam a morte social destes individuos negros e negras que, dificilmente, por conta do estigma social, terão restituido o seu status, já maculado pela opressão racial em todos os campos da vida, de cidadania ou possibilidade de alcançá-la. (BORGES, 2019, p. 22).

Ainda que a maior parte do contingente prisional seja do sexo masculino, representando um percentual de $94,3 \%$ em face dos $5,7 \%$ de mulheres, revela-se fundamental uma atenção à condição feminina nesse espaço, sobretudo em um contexto de risco pandêmico. As condições atuais aumentam a preocupação com a situação, tendo em vista os dados trazidos pela OAB/SE (2018) que, na avaliação do Presídio Feminino do Estado de Sergipe (Prefem) 7 . elenca o fato de que na unidade prisional está superlotada com cerca de 235 mulheres, sendo que a capacidade é para 175 usuárias. Não existindo tendência à mudança, trata-se de um cenário que preocupa, sobretudo devido ao alastramento da pandemia, e a necessidade de garantias mínimas de "distanciamento social".

\footnotetext{
7 A instituição está localizada no município de Nossa Senhora do Socorro (SE), e a gestão é de competência do Estado.
} 
Não bastasse o contexto de superlotação, o referido relatório aponta, ainda, alguns problemas na unidade feminina, tais como: ausência de algumas especialidades médicas, inclusive com insuficiência de técnicos de enfermagem; falta de manutenção de medicações para algumas comorbidades, como diabetes, hipertensão, tratamento psicológico, entre outros; não há reposição de forma regular em relação a alguns materiais e aparelhos como: algodão, gazes, tensiômetro, glicosímetro e aparelho de aerosol; número de agentes penitenciários inferior ao que de fato é exigido para garantir a segurança no local, e que também impossibilita a escolta das mulheres na realização de exames (OAB/SE, 2018). Trata-se, então, de uma série de "debilidades institucionais", que acabam por tornar essas mulheres mais vulneráveis quanto à possibilidade de maior exposição ao contágio pela Covid-19.

Como já visto, o quadro da unidade prisional feminina se insere no complexo geral das condições dos presidios sergipanos, que acabam constituindo-se como um componente potencialmente catalisador das mesmas condições sociossanitárias propícias à expansão pandêmica. Conforme Bertoni (2020) em noticiário do Nexo Jornal, o defensor público em São Paulo e vice-presidente do Instituto Brasileiro de Ciências Criminais (IBCCRIM), Bruno Shimizu, enfatizou a duplicação de mortes dentro das prisões brasileiras até junho de 2020, devido à situação de pandemia, comparado ao ano de 2019. Entre julho e setembro, o número de casos entre privados de liberdade aumentou 287\%8. $\bigcirc$ defensor Bruno destacou as péssimas condições em que vivem os(as) encarcerados(as) nos espaços de reclusão, como a superlotação das celas, divisão de colchões entre os(as) internos(as), racionamento de água, pouca ventilação, e as equipes de saúde cumprem suas atividades em apenas um terço das unidades, o que propicia um alto risco de infecção pelo coronavírus.

A gestão da pandemia no cárcere tem sido um projeto necropolítico, ou seja, um projeto de deixar morrer, não produzir dados, trabalhar com a subnotificação e fazer com que esse genocídio que está acontecendo dentro dos presídios não se escreva sequer na memória coletiva da população, na medida em que sequer os exames estão sendo feitos. (BERTONI, 2020, n.p).

8 Disponivel em: https://www.cnj.jus.br/covid-19-casos-entre-privados-de-liberdade-aumentam-287-em-90dias/?utm_source=dlvr.itEutm_medium=facebookEutm_campaign=covid-19-casos-entre-privados-de liberdadeaumentam-287-em-90-dias. 
Borges (2019, p. 20) enfatiza um relevante mecanismo de configuração enraizado estruturalmente e que se reconfigura no sistema penal, tendo na necropolítica o fundamento dessa sociabilidade, a partir do conceito elaborado pelo sociólogo camaronês Achile Mbembe: o poder de ditar quem deve viver e quem deve morrer. É um poder de determinação sobre a vida e a morte ao desprover o status político dos sujeitos. A diminuição ao biológico desumaniza e abre espaço para todo tipo de arbitrariedade e inumanidade. Essa dinâmica nas particularidades nacionais é parte do "projeto genocida brasileiro" (FLAUSINA, 2008) e é fruto de um processo histórico, de correntes que escravizaram e que ainda escravizam através das amarras históricas, econômicas, sociais, político-ideológicas, culturais e simbólicas que servem para a manutenção dessa ordem, correntes essas que condicionam sujeitos ao cárcere.

Todo o quadro apontado revela o nivel de exposição à qual é submetida essa população nos presidios sergipanos como particularidade do contexto nacional. Tal população, em um cenário de profunda crise sanitária, tem seus níveis de exposição e risco de morte amplificados pela propagação da pandemia, agravadas pelas condições em que subsistem as instituições prisionais, configurando-se, em verdade, como "depósitos dos indesejáveis" (WACQUANT, 2011, p. 123).

\section{AS AÇÕES DE MITIGAÇÃO DA EXPANSÃO DA COVID-19 NOS PRESÍDIOS EM SERGIPE}

Diante de todo o quadro exposto, cumpre problematizarmos: que medidas vêm sendo adotadas para minorar os efeitos da pandemia nos presidios sergipanos? Antes, porém, vale a pena situarmos o quadro geral da pandemia, em nível nacional. $O$ país já se encontra na casa de mais de185 mil mortes por Covid-199, em mais ou menos 9 meses, e, ainda assim. amplia-se a flexibilização das medidas de distanciamento social, com a abertura do comércio e shopping como se tudo estivesse em normalidade? Se temos esse resultado, considerando um cenário de "sujeitos visíveis" - para as estatísticas, mídia e possibilidade de ação governamental -, então como se apresenta a situação das pessoas que se encontram em privação de liberdade, como é o caso do sistema prisional? Cumpre destacar a denúncia feita

9 Disponivel em: https://gl.globo.com/jornal-nacional/noticia/2020/12/18/brasil-passa-de-185-mil-mortes-porcovid.ghtml. Acesso em 12 de dezembro de 2020. 
junto à Organização das Nações Unidas (ONU) contra o governo Jair Bolsonaro em virtude da negligência do Estado brasileiro às questões de situação prisional10. Ainda que tenham poucas notificações, o número de mortes nos presídios chega a ser cinco vezes maior que no restante da população (CHADE, 2020). Ademais, o número de contaminação corresponde a um dado ainda subnotificado, se se levam em consideração os poucos testes realizados nesses locais, que atendem apenas $0,1 \%$ da população prisional (CHADE, 2020).

Conforme o Ministério da Saúde, no mês de março, Sergipe contava com 2.200 casos confirmados de Covid-19. No mesmo mês, no Complexo Penitenciário Dr. Manoel Carvalho Neto (Copemcan), toda a ala do pavilhão do presídio foi isolada após suspeita de contaminação de quatro presos(as) após uma visita. A Secretaria do Estado de Segurança Pública informou que. após esse caso, a diretoria estava pensando estratégias para conter o alastramento do vírus nos presidios (CONJUR, 2020).

De acordo com o site Conjur (2020111, o Grupo de Monitoramento e Fiscalização do Sistema Carcerário (GMF) do Tribunal de Justiça do Estado de Sergipe viabilizou a emissão de ofício aos(às) juízes(as) responsáveis pelas áreas criminais com o intuito de estes(as) realizarem uma avaliação em torno da prisão provisória ou definitiva dos(as) usuários(as) privados de liberdade maiores de 60 anos e gestantes como forma de prevenção ao coronavírus.

No final do mês de abril, de acordo com o site G1 (2020), a Sejuc confirmou o primeiro caso de Covid-19 no estado12. E, ainda nesse mês, 99 internos(as) que faziam parte do "grupo de risco" foram liberados dos presídios em Sergipe. Essa medida foi adotada após a recomendação do CNJ no $62^{13}$. Além disso, em virtude da restrição das visitas nos presídios

\footnotetext{
${ }^{10}$ Conforme noticia divulgada pela Organização das Nações Unidas (ONU) e a Organização dos Estados Americanos (OEA), receberam uma denúncia contra o governo de Jair Bolsonaro, acusado de estar negligenciando a situação da pandemia nas prisões e de liderar uma "política genocida". Para mais de 200 entidades que assinam a queixa formal, o alastramento da pandemia está acelerando o colapso nas prisões brasileiras (CHADE, 2020).

11 Judiciário se mobiliza para prevenir Covid-19 em presídios. Consultor Jurídico. Disponível em: https://www.conjur.com.br/2020-mar-26/judiciario-mobiliza-prevenir-covid-19-presidios. Acesso em: 12 jun. 2020. 12 Segundo a notícia, um jovem de 25 anos foi transferido para o Hospital de Urgência de Sergipe, ao retornar ficou isolado no pavilhão de triagem no presídio de Areia Branca para evitar aglomerações, mas necessitou retornar ao hospital, recebendo o atendimento necessário.

13 O Tribunal da Justiça de Sergipe informou que essa liberação não foi realizada de forma generalizada e sim. a partir da análise de cada caso pelo Juiz, levando em consideração não só os impactos inerentes à contaminação do virus, mas também o risco de soltura do preso em relação às vítimas e testemunhas.
} 
do estado, a Defensoria Pública do Estado de Sergipe recomendou a implementação do sistema virtual de comunicação entre os presos(as) e seus familiares.

No dia 6 de maio de 2020, conforme relata Rios (2020), em matéria do Jornal da Cidade, morreu, no Hospital de Urgência de Sergipe (Huse), Laio Hérico Campos dos Santos, de 32 anos, que estava custodiado no Complexo Penitenciário Antônio Jacinto Filho (Compajaf), sendo o registro do primeiro óbito por contaminação do Covid-19 no sistema prisional sergipano, segundo o mesmo jornal. Ainda na mesma matéria, a Comissão de Direitos Humanos da Ordem dos Advogados do Brasil em Sergipe (OAB/SE) solicitou um posicionamento à Sejuc em relação às medidas que estavam sendo tomadas nesses espaços, o número de encarcerados(as) e funcionários(as) que testaram positivo, casos suspeitos, isolamentos, estrutura de atendimentos, entrega de kit de higiene, comunicação virtual entre os usuários(as) e seus familiares, e as medidas sanitárias como forma de desinfectar as unidades que compõem o sistema prisional. Considerando a particularidade do sistema carcerário, revela-se importante a preocupação do presidente da Comissão de Direitos Humanos da OAB/SE, Robson Barros, no impacto que a entrada do vírus nos presídios poderia causar no âmbito do sistema de saúde público, num período, aliás, cujo risco de colapso já estava no horizonte.

O site Justificando (2020) destaca o que o Plano Nacional de Saúde do Sistema Penitenciário estabelece para atendimentos daqueles(as) que estão em privação de liberdade: uma equipe para cada 500 presos. Conforme nota técnica 23/2020 de 5 de abril de 2020 . emitida pela Coordenação de Saúde do Depen, subordinada ao Ministério da Justiça, em resposta à Recomendação 62 do CNJ, como ressalta o site Justificando (2020), dentro das unidades prisionais, os serviços de saúde não seriam precários, ao comparar com a população em geral. Entretanto,

[a] própria nota afirma que a "cobertura das equipes PNAISP não é homogênea em todo o país. Alguns estados possuem grande cobertura como Distrito Federal, Pernambuco e Mato Grosso do Sul, com 95\%, 85,1\% e 76\% e estados como Amapá, Sergipe e Paraiba, com baixa cobertura, entre $0 \%$ e $2.6 \%$ " e faz a ressalva que "algumas secretarias de Administração Prisional possuem profissionais de saúde em seu quadro próprio e ainda Estados que ofertam os serviços de saúde nas unidades prisionais através de Organização Sociais". (JUSTIFICANDO, 2020). 
Como se observa, dentro dessa dinâmica não homogênea dos serviços de saúde nos diferentes estados, verifica-se o estado de Sergipe com baixa cobertura, situação que, num contexto de crise sanitária, torna-se alarmante. Além disso, a condição de atendimento em saúde não parece se constituir como um dado isolado, mas como parte da própria estrutura precária dos presídios no país, uma lógica que torna esses corpos "objetos" descartáveis, indignos de vida (D'ELLIA FILHO, 2015). De acordo com o Relatório Final da Comissão Parlamentar de Inquérito da Câmara dos Deputados em 2009, destacavam-se as seguintes informações a respeito da não existência da equipe médica de saúde de forma suficiente nesses espaços: dos cerca de 422.590 presos(as) existentes no Brasil (dezembro de 2007). aproximadamente 87.000 , ou seja, apenas $20 \%$ (vinte por cento) se encontravam cobertos pelas Equipes de Saúde. (JUSTIFICANDO, 2020). O site Justificando (2020) mencionou o posicionamento por meio de uma entrevista do subprocurador-geral da República e coordenador da Câmara do Sistema Prisional, Domingos Sávio Dresch da Silveira, no dia 30 de março de 2020 à Folha de São Paulo:

'Aquilo que se entende por assistência [nos presídios] é, quando muito, um médico duas vezes por semana. Não é um pequeno hospital, uma enfermaria'. Ele diz que há casos em que uma unidade com 3.000 detentos é visitada por médico apenas duas vezes por semana, com capacidade para atender 15 pessoas por vez (...) Apesar da maior susceptibilidade às doenças, o acesso dos presos à assistência é bem pior, em termos proporcionais, que o do restante dos brasileiros [.... (JUSTIFICANDO, 2020).

Na mesma reportagem, o professor da Faculdade de Medicina da Universidade de São Paulo (USP) Mário Scheffer destacou que: "Não tenho dúvida de que uma epidemia sem retaguarda [médica] vai dizimar parte da população carcerária, há risco de disseminação maior e, obviamente, vai ser" (JUSTIFICANDO, 2020). Considerando as dificuldades evidenciadas na afirmação dessa retaguarda, torna-se patente como o Estado brasileiro tem mobilizado sua política criminal, em que a população prisional se constitui como "vidas indignas" (D'ELIA FILHO. 2015).

No dia 5 de junho, conforme a notícia disponibilizada no site do Governo do Estado de Sergipe (2020), estavam sendo executadas diversas ações, como, por exemplo, orientação sobre a importância da frequente higienização das mãos, uso de álcool em gel, distribuição 
de máscaras para evitar o contágio pelo vírus no sistema prisional sergipano, sendo adotadas as medidas previstas no plano de contingência. No mês de julho, o estado constatou 13 casos e um óbito no sistema prisional, resultantes da Covid-19.

Segundo o Departamento Penitenciário Nacional (Depen), foi realizada no estado de Sergipe no sistema prisional a suspensão total quanto às visitas. $\bigcirc$ mesmo órgão divulgou em seu site termos de recebimento de material de higiene para prevenção à contaminação pelo coronavírus no estado de Sergipe. Ainda de acordo com o Depen, desde o dia 20 de março de 2020 foram tomadas as seguintes medidas no sistema prisional sergipano: adoção de prisão domiciliar (que se enquadrem nas hipóteses concessivas legais); suspensão de visitas aos internos; triagem na entrada da unidade prisional; triagem na inclusão do interno; suspensão de atendimento de advogados, defensoria pública; elaboração de nota técnica; assepsia diária das celas; limitação/suspensão de transferências entre unidades da Federação; uso de tornozeleiras eletrônicas para presos(as) do semiaberto; isolamento de internos maiores de 60 anos ou com doenças crônicas; aumento do tempo diário do banho de sol; isolamento de sintomáticos em celas. O órgão disponibilizou as medidas concessivas adotadas pelo sistema prisional no estado a familiares/visitantes e presos(as) durante o periodo de suspensão das visitas.

De acordo com o Boletim Semanal - CNJ/Covid-19, até 30 de setembro de 2020, em Sergipe, contabilizava-se um total de 473 testes realizados, sendo identificados 224 casos de infecção no sistema prisional, além de dois óbitos registrados ${ }^{14}$. Por outro lado, no resultado de testagem divulgado pela Universidade Federal de Sergipe (UFS), tem-se a informação da realização de 800 testes com a detecção de 448 casos de contaminação, ou seja, pouco mais da metade da população carcerária $(56 \%)^{15}$ testou positiva para o vírus, dado que ilustra com "requintes de crueldade" a pandêmica situação dessa população. Apesar das informações distintas entre as duas divulgações, o número de testes ainda se revela bem aquém do necessário, considerando o total de mais de 6.000 presos(as), incorrendo em um processo de preocupante subnotificação, dificultando o estabelecimento de um real panorama da situação.

\footnotetext{
14 Informação disponivel em: https://www.cnj.jus.br/wp-content/uploads/2020/10/Monitoramento-SemanalCovid-19-Info_14out.pdf. Acesso em: 17 out. 2020.

15 Disponivel em: https://infonet.com.br/noticias/saude/covid-19-56-da-populacao-carceraria-de-sergipetestaram-positivo/. Acesso em: 17 out. 2020.
} 
sobretudo diante da possibilidade de retomada das visitas e maior contato com familiares, expondo mais pessoas a essa situação.

Como destacamos, várias ações, sobretudo de caráter governamental, podem ter contribuido para diminuir um maior impacto da pandemia nos espaços prisionais. Entretanto, frente a um quadro de grande subnotificação, não dispomos ainda de uma real avaliação desse impacto, o que se mostra bastante preocupante. Além disso, todos os dados revelam a "pandemia perene" do próprio sistema prisional e a violação permanente de direitos em que se encontram os(as) internos(as) que ali estão. Foi possivel identificarmos que a estrutura pela qual se assenta o sistema prisional em Sergipe, tal qual no restante do pais, afirma-se como um mecanismo potencializador da expansão da Covid-19, o que acentua os riscos para oslas) internos(as). Mas vale destacarmos que antes esse mesmo cenário já facilitava o ingresso, expansão e letalidade de tantas outras doenças infectocontagiosas, assentando que tal sistema, em si, já se constitui um "risco" maior que a própria pena aplicada. Dessa incessante condição pandêmica, tem sido alvo a população negra, jovem e pobre, o que reafirma um controle estatal permanente sobre esses sujeitos; e esse é, como dissemos, o grande desafio ao repensarmos o sentido e a funcionalidade da prisão nessa sociabilidade.

\section{CONSIDERAÇÕES FINAIS}

Mediante o que foi abordado, é importante pensarmos nos aspectos que foram mencionados neste trabalho, na tentativa de provocar aolà) leitor(a) reflexões sobre a situação das pessoas em privação de liberdade, com ênfase no sistema prisional, nesses tempos de pandemia e com todas as implicações dela decorrentes no aprofundamento da violação de direitos. Se antes mesmo já viviam sob péssimas condições, a tendência, diante das peculiaridades advindas de uma crise pandêmica, de escala planetária, é que essas condições se tornem ainda mais precárias e se aprofundem no sistema carcerário nesse período.

Se historicamente a situação nos presidios é comparada a um "terreno baldio" das políticas públicas, refletindo a desigualdade estrutural do capitalismo que se acirra nos marcos do projeto neoliberal, em que se verifica uma ampliação dos mecanismos de controle e gestão 
da população excedentária ao processo de submissão direta à exploração do capital, é certo que no periodo da pandemia essas desigualdades se tornam ainda mais evidentes e, por outro lado, com maiores prejuízos àqueles(as) que são configurados como "invisiveis" ou "esquecidos". mas que, em verdade, constituem-se como sujeitos privilegiados da ação punitiva do Estado capitalista, incrementada em tempos de crise sistêmica.

É importante lembrar quem são essas pessoas sujeitas à "mão firme" do Estado: majoritariamente jovens, negros(as), com baixa escolaridade, pertencentes à classe explorada, que são os(as) mais "vulneráveis", "alvos privilegiados" do controle punitivo. Sendo assim, conforme indica Borges (2019, p. 19), é necessária [...] mais do que uma reforma no sistema de justiça criminal, mas total e estrutural transformação e reconstrução deste mecanismo ou, no caso das prisões, sua abolição. É fato que a pandemia acentuou as contradições dessa sociabilidade que se nutre pela desigualdade, reproduzida em expressões assimétricas de classe, gênero e raça, azeitada pelo recurso permanente à ação punitiva do aparelho estatal, contribuindo para um processo de violação sistemática de direitos. Mas o que esperar do pós-pandemia? O desafio será como superar tais desigualdades e, no que concerne ao objeto do presente artigo, desmistificar o caráter necessário e perene do cárcere, o que passa pela crítica radical dessa forma social e seus correlatos sistemas punitivos, inclusive a prisão.

\section{REFERÊNCIAS}

ALEXANDER, Michelle. A nova segregação: racismo e encarceramento em massa. Tradução de Pedro Davoglio. Revisão técnica e notas de Silvio Luiz de Almeida. 1. ed. São Paulo: Boitempo, 2017.

ALMEIDA, Silvio Luiz de. O que é racismo estrutural? Belo Horizonte (MG): Letramento, 2018.

ARAÚJO et al. Sistema Prisional Brasileiro, com ênfase no Estado de Sergipe: Problemas e observância ao Ordenamento Jurídico. Cadernos de Graduação Ciências Humanas e Sociais, Aracaju, v. 2, n. 2, 2014. Disponivel em: periodicos.set.edu.br. Acesso em: 12 jun. 2020.

BERTONI, Estêvão. O avanço da covid-19 nas prisões. E a subnotificação dos casos. NEXO, 18 jun. 2020. Disponivel em: https://www.nexojornal.com.br/expresso/2020/06/17/0avan $\%$ C 3\%A7o-da-covid-19-nas-pris \%C 3\%B5es.-E-a-subnotifica \%C3\%A7\%C3\%A3o-decasos. Acesso em: 22 jun. 2020.

BORGES, Juliana. Encarceramento em massa. São Paulo: Pólen, Coleção Feminismos Plurais, 2019. 
BRASIL. Sejuc. Lei no 8.633 de 27 de dezembro de 2019. Disponível em: https://se juc.se.gov.br/wp-content/uploads/2020/03/Lei-8.633-19_alteraaltribui\%C3\%A7\%C3\%B5es-SEJUC.pdf. Acesso em: 12 jun. 2020.

BRASIL. Relatório Consolidado Nacional/2019. Sistema Brasilia: Ministério da Justiça e Segurança Pública. Departamento Penitenciário Nacional, Sistema de Informações do Departamento Penitenciário Nacional (SISDEPEN), 2019.

BRASIL. Secretarias Estaduais de Saúde. Brasília, Distrito Federal: 2020. Disponível em: https://covid.saude.gov.br/. Acesso em: 11 set. 2020.

BRASIL. Ministério da Justiça. Lei de Execuções Penais. Brasilia, Distrito Federal: Senado Federal, 1984.

BRASIL. Ministério da Justiça. Levantamento Nacional de Informações Penitenciárias. 2019. Disponivel em: http://dados.mj.gov.br/dataset/infopen-levantamento-nacional-deinformacoes-penitenciarias. Acesso em: 11 set. 2020.

CHADE, Jamil. Denúncia na ONU: pandemia aprofunda política genocida do governo em prisões. UOL, 23 jun. 2020. Disponivel em: https://noticias.uol.com.br/colunas/jamilchade/2020/06/23/denuncia-na-onu-pandemia-aprofunda-politica-genocida-do-governo-emprisoes.htm. Acesso em: 25 jun. 2020.

CONJUR. Judiciário se mobiliza para prevenir Covid-19 em presídios. Consultor Jurídico, 26 mar. 2020. Disponivel em: https://www.conjur.com.br/2020-mar-26/judiciario-mobilizaprevenir-covid-19-presidios. Acesso em: 12 jun. 2020.

D'ELIA FILHO, Orlando Zaccone, Indignos de vida: a forma jurídica da política de extermínio de inimigos na cidade do Rio de Janeiro. Rio de Janeiro: Revan, 2015.

DEPEN. Levantamento Nacional de Informações Penitenciárias. Atualização - junho de 2017. MOURA, M. V. (Org.) Brasilia: Ministério da Justiça e Segurança Pública, Departamento Penitenciário Nacional, 2017.

DEPEN. Perfil da população carcerária do Brasil e estados. Brasilia. Distrito Federal: Ministério da Justiça - Departamento Penitenciário Nacional, dez. 2019. Disponível em: https://app.powerbi.com/view?r=eyJrl joiN2ZIZWFmNzk+NjRIZiOOMjNiL WFhYmY+NjExNmMyNmY xMjRkliwidCl6lmViMDkwND/wLTQONGM+NDNmNy05MWY yLTRiOGRhNmJmZThIMSJ9. Acesso em: 11 set. 2020 .

FBSP. Anuário Brasileiro de Segurança Pública. Brasilia, 2019 [lnternet]. Disponível em: http://www.observatoriodeseguranca.org/download/13-anuariobrasileiro-de-segurancapublica-2019. Acesso em: 16 fev. 2020.

FERNANDES, Florestan. A Integração do Negro na Sociedade de Classes. Volume I. Ensaio de Interpretação Sociológica. 5. ed. São Paulo: Globo, 2008.

FLAUZINA, Ana Luiza Pinheiro. Corpo negro caído no chão. O sistema penal e o projeto genocida do Estado brasileiro. Rio de Janeiro: Contraponto, 2008. 
G1 SERGIPE. 13 casos do novo coronavírus foram confirmados em internos do sistema prisional de Sergipe. G1. Sergipe, 3 jul. 2020. Disponivel em: https://gl.globo.com/se/sergipe/noticia/2020/07/03/13-casos-do-novo-coronavirus-foramconfirmados-em-internos-do-sistema-prisional-de-sergipe.ghtml. Acesso em: 22 jul. 2020.

JUSTIFICANDO. Superlotação do sistema carcerário e a pandemia do coronavírus. Justificando, 25 maio 2020. Disponivel em: https://www.justificando.com/2020/05/25/a-superlotacao-dosistema-carcerario-e-a-pandemia-do-coronavirus/. Acesso em: 29 maio 2020.

MARX, Karl. O Capital. Crítica da Economia Política. Livro 1. São Paulo: Boitempo, 2013.

MELOSSI. Dario; PAVARINI, Massimo. Cárcere e fábrica: as origens do sistema penitenciário (séculos XVI e XIX). 2 ${ }^{\text {a }}$ reimpressão. Rio de Janeiro: Revan/ ICC, 2017.

MÉSZÁROS, István. Para além do capital: rumo a uma teoria de transição. São Paulo: Boitempo Editorial, 2002.

NASCIMENTO, Abdias. Democracia racial: mito ou realidade? 1977. Disponível em: https://www.geledes.org.br/democracia-racial-mito-ou-realidade/. Acesso em: 15 set. 2020.

OAB/SE. Relatório: Sistema Prisional do Estado de Sergipe. 26 mar. 2018. Acesso em: 17 jul. 2020.

RIOS, Diego. Sistema prisional sergipano registra primeira morte por covid-19. Jornal da cidade. Sergipe, 14 maio 2020. Disponivel em: http://www.jornaldacidade.net/cidades/2020/05/317571/sistema-prisional-sergipano-registraprimeira-morte-por-covi.html. Acesso em: 20 maio 2020.

SANTOS, Ruth. Conceição. Farias. Representações Sociais de Aprisionados (as) e Técnicos(as), sobre os Programas de Ressocialização (Atividades de Educação e Trabalho) no Sistema Prisional de Sergipe. 2012. Dissertação (Mestrado em Educação) - Universidade Federal de Sergipe (UFS), São Cristóvão, Sergipe, 2012. Disponível em: https://ri.ufs.br/bitstream/riufs/4661/1/RUTH_CONCEICAO_FARIAS_SANTOS.pdf. Acesso em: 11 jul. 2020.

WACQUANT, Loïc. As prisões da miséria. Rio de Janeiro: Jorge Zahar Ed., 2011. 